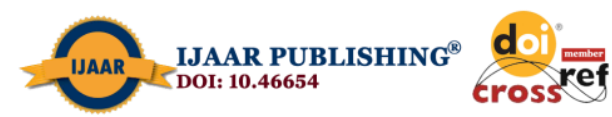

International Journal of Advanced Academic Research (Social and Management Sciences) | ISSN: 2488-9849

Vol. 6, Issue 11 (November, 2020) | www.ijaar.org

Journal DOI: 10.46654/ij.24889849

Article DOI: 10.46654/ij.24889849.s6113

\title{
ORGANIZATIONAL MINDFULNESS AND CORPORATE RESILIENCE OF HOSPITALITY FIRMS IN RIVERS STATE, NIGERIA
}

\author{
Isirimah Nnamdi $\mathbf{N}$. \\ University of Port Harcourt Business School, Port Harcourt, Rivers State, Nigeria. \\ B. Chima Onuoha \\ Department of Management, University of Port Harcourt Choba, Rivers State, Nigeria.
}

\begin{abstract}
This study is an empirical inquiry into the adoption and practice of metaphysical components such as organizational mindfulness in management and its relationship with social realities such as organizational resilience in Nigerian businesses, specifically as it applies to Hospitality Firms in Rivers state, Nigeria. As a cross sectional survey, data for the study was generated using structured questionnaire from 39 respondents across 8 sampled registered hospitality firms. A total of three hypotheses were postulated with analysis revealing significant correlations between organizational mindfulness and the measures of organizational resilience; Affective commitment, organizational involvement and Customer Satisfaction; implying that the adoption and practice of organizational mindfulness is a prerequisite for effectively attending to and addressing work-related issues and thus enhancing organizational resilience. In conclusion, the findings of this study lend credence to its support for the adoption and practice of organizational mindfulness in achieving a more sensitized and supportive work environment and thereby a more desirable expression of work attitudes from employees. It was thereafter recommended that organizations should on a consistent basis, assess their dispositions and the applicability of their systems and technologies within their various contexts. The applicability of such features determines their effectiveness and also impacts on their resilience.
\end{abstract}

Keywords: Organizational mindfulness, Corporate Resilience, instrumental, threats, opportunities. 


\section{INTRODUCTION}

Companies are expected to deal with current and upcoming demands concurrently in today's complex market climate, and they are also expected to be able to mix repetitive action with improvisation (Dagogo \& Gublin, 2020). As such, the ability to adapt successfully advances the chances of success of companies within their present setting as well as their expected location in the future. Organizational resilience may also be defined as consisting of both strategic and organizational features. Organizational resilience is known in this paper as the capacity of an entity to fathom its dynamic interaction with the outside environment. This requires a method of sensing consisting of three different phases: noticing, interpreting, and behaving (Schilling, 2000). Huber (2004) argued that the cumulative sensing effort of all organizational participants depends on organizational resilience. This is also focused on what was described as modular organizing by Sanchez and Collins (2001). The combination of independent organizational units into personalized constellations is known as modular organisation (Sanchez, 2003; Schilling, 2000; Worren, Moore, \& Cardona, 2002). Sanchez and Collins (2001) demonstrate that growing operational stability without jeopardizing efficiency is the primary merit of modularization.

Organizations are now facing evolving and rising environmental challenges and are being challenged to strengthen their ability to respond to new strategic scenarios on an ongoing basis. Among others, population developments, competitiveness and the changing complexities of modern market activities have been the most prominent stresses quoted in literature, leading to the rise of a more global economy (Okpu \& Gbaraka, 2019), which appears to be involved in the economic environment and is now forcing businesses to create alternative ways of organizing (Graetz \& Smith, 2009). In addition to being successful in their organizational routines, organizational resilience will rely on being creative at the same time (Graetz \& Smith, 2009).

Organizational resilience literature started more than six decades ago and has been correlated with many organizational strengths (agility, mobility, adaptability, fit, and flexibility). A large number of studies demonstrate how firms, through their focus on sensitive structures and procedures, can gain and maintain competitive advantages, build capacities to control and affect their environment, and handle chaos and adversity. As a central imperative for the sustainability and competitiveness of organizations in volatile and uncertain settings, corporate stability has recently gained increasing recognition from both scholars and managers (Dreyer \& Gronhaug, 2004) and it is becoming the modern hallmark of organizational success (Volberda et al., 2007). Previous study data also confirms the correlation between internalized experiences or beliefs of workers and their attitudes towards work and their organisations, as Paarlberg and Perry (2006) explored the management of values in terms of aligning employee values and goals with those of the company through repetitive procedures that involve everyday encounters in the workplace between management Despite all of these, though, there is no data that recognizes or connects leadership knowledge as a spiritual aspect of management to the effects of social realities within the African workplace, such as employee job attitudes.

This research contributes by exploring the link between leadership awareness; a metaphysical aspect of management; and social realities such as employee job attitudes within Nigerian companies, especially Hospitality Companies in the State of Rivers, Nigeria. The importance of this study is focused on its methodological approach to investigating the relationship between 
leadership knowledge and employee job attitude, especially as it relates to selected hospitality companies in the state of Rivers, Nigeria; given the lack of research and literature documenting such a relationship within the country considering its reputation for the average employee in the public sector This is how Chaskalson (2011) explains mindfulness in a pattern that makes for a more rational and constructive solution to challenges as a non-biased way of perceiving and attending to oneself, others and one's environment. The relative effects of the employee work attitudes analyzed include organizational engagement, workplace participation and job happiness (Gabriel and George, 2015) as a consequence of the practice or nature of leadership understanding in the state of Rivers, Nigeria, within hospitality firms.

According to Hatum and Pettigrew (2006), because of their obvious lack of adequate models describing the relationship between organizational sensitive capacities, environmental instability and the success of the corporation (Suarez, Cusumano \& Good, 2003) in the business life cycle (Dreyer \& Gronhaug, 200), managers face significant difficulties in achieving organizational reform without compromising equilibrium The dimensionality of organizational resilience (Hatum \& Pettigrew, 2006), its relationship with business scale (Kraatz\& Zajac, 2001), the context specificity of resilience capacities and organizational architecture (Volberda, 1998; Verdú-Jover, Lloréns-Montes and Garcia-Morales, 2005; Martínez-Sánchez, et al., 2009) have arisen and empirically illustrate various methods. The apparent difference between the mixture of the organizational variables defined (size, nature, function, etc.) and their suitability for individual conditions specifies the need for consciousness within the organisation as a collective condition.

Different academic bodies have drawn on the effort to explain the corporate reaction to challenges and opportunities that contribute to contradictory conclusions. For example, experiments that adopt the principle of danger rigidity (Staw et al., 1981) suggest that threat analysis strengthens organizational inertia by restricting alternatives and focusing on previous experienced rituals (Dutton \& Jackson 1987; Staw et al., 1981), while the sense of opportunity makes the possible benefits more important than the risks involved (March \& Shapira, 1987) Nonetheless, even in contemporary literature, research that have explored the function of organizational mindfulness as an indicator of resilience continue to be rare and seldom discussed. This thesis provides a departure from previous studies when it explores the hypotheses that connect both structures.

\section{Literature Review}

\section{Theoretical Framework}

\section{The Institutional Theory}

In discussing the relationship between organizational mindfulness and resilience in this review, the institutional theory is considered adequate. Institutional theory offers a basis for how organisations within their system react to institutional and contextual demands (Zucker, 1987). Companies respond to a mix of internal and external corporate pressures in such a way that the idea indicates that market activities appear to overlap among different organisations. Homogeneity or what can be defined as continuity of behavior is the premise underlying the 
institutional theory. The value of establishing and preserving credibility among organizational stakeholders was stated by Grewal and Dharwadkar (2002) in the convergence phenomenon.

Meyer and Rowan (1977) argue that the strategies and processes originating from existing rationalized principles of organizational work and institutionalized within their own operating environments are guided by organisations to embrace and apply them. Organizations will try to improve their credibility and their chances for success by a mutual understanding of current processes and standards, regardless of the immediate usefulness of learned practices and procedures. Meyer and Rowan (1977) describe institutional rules as collectively formed classifications as reciprocal types or meanings and agree that such rules may simply be taken for granted or supported by the power of law or popular opinion. Moreover, Meyer and Rowan (1977) suggest that institutionalization requires the mechanisms by which social processes, roles, or realities take a rule such as social thinking and behavior status.

\subsection{Conceptual Framework}

\section{Organizational Mindfulness}

Organizational mindfulness is demonstrated in increasingly complex and time-sensitive settings by organisations that work effectively (Weick \& Sutcliffe 2006). This view relies on the premise that there are novel elements in each modern scenario and that taking something for granted is a dangerous endeavour in a routine-like fashion (Weick et al., 1998). Given their ability to both predict and contain the unforeseen, mindful organisations are also successful in their objective accomplishment and efficacy. One way of predicting the inevitable is to think about loss, which involves paying attention to the minor and big errors that may arise in an organisation. Increased exposure to future errors ensures an ongoing sense of emerging technical vulnerabilities, weaknesses in current processes, and sloppiness in the organization's structures or operations (Weick \& Sutcliffe, 2006), which may in itself help avoid errors from arising.

Mindfulness is not about "being conscious" of single persons or investing in meditative rituals. Rather, it is about organizational habits that contribute to a quality of organizational focus that increases the risk of individuals recognizing and acting on specific information of circumstances (Weick \& Sutcliffe, 2006). By counteracting the propensity to simplify events into common categories and by enhancing the capacity to anomalize events, Mindfulness works (Weick \& Sutcliffe, 2006). In effect, mindfulness both increases the variation needed and strengthens its utility.

The required variety law notes that the variety of a structure such as an agency, team, or entity must be as large as the variety of the world it is attempting to manage (Sutcliffe, 2000). "It is often believed that" requisite "is random variety, however, in fact, the form of variety brought to bear is crucial (Dimov, Shepherd, \& Sutcliffe, 2007). The range that more mindful organisations are searching for is that which offers insight into their individual environments and ongoing activities. Furthermore, while the appropriate variation is a crucial building block of adaptability, context depends on the ability to use the variation. Consequently, attentive organization is the way by which companies can build and rely on the necessary spectrum and thereby underpin adaptability capabilities. 
Organizations with access to a wealth of experience and experiences are likely to track the environment more broadly and are thus more likely to find signals that change is required (Sutcliffe, 2000). This happens in two respects. Second, multiple environmental viewpoints are expected to reveal various signals. For example, a marketing specialist is more likely to notice that consumer tastes are shifting, whereas a specialist in operations will notice that manufacturing conditions are likely to slow down future production. Second, with their own worldview, multiple entities are likely to frame the corporate situation, offering insight into possible challenges or openings that others do not notice.

In addition to having a greater surveillance coverage, the diversity of criteria is also likely to result in earlier detection of the need for adaptation. Sometimes, the first signals that adaptation is expected are very weak, only apparent to some areas of the structure. The loss of a small customer, for example, could be meaningless to the company as a whole, but for someone who understands that that customer represents the organization's new target demographic, such a loss is an indication that the new value proposition is not working. Early understanding of this cue can mean the difference between an early small change in strategy and a later big recovery attempt (Dimov et al., 2007).

\section{Organizational resilience}

Organizational resilience can be characterized as the tendency of a firm to act on the basis of generated market knowledge (Hult et al., 2005). Kohli and Jaworski (1990) reflect organizational resilience to the use of information within the enterprise, which consists of two sets of activities: response design (the use of market intelligence to create plans) and execution of response (the use of market intelligence to execute those plans) (Kohli \& Jaworski 1990). Several unique aspects of organizational resilience have also been defined by Kohli and Jaworski (1990), including the identification of target audiences, the design and delivery of goods and services that satisfy the actual and intended needs of consumers, and the manufacture, delivery and marketing of products in a manner that generates favorable end-customer response (Kohli \& Jaworski, 1990).

The view of the use of intelligence varies from a cognitive approach, which is based on the view that the behavior of organizations are influenced by how managers interpret their situations and make sense of them and convert those perspectives into strategic decision (Thomas et al., 1993). The institutional theory presents a position that strengthens the perception of the relationship between organisations and their environment, and the propensity to innovate. As Kohli and Jaworski (1990) have pointed out, shifting consumer conditions call for the implementation of new goods and services to satisfy the emerging market and environmental needs.

However, the implementation of new and updated services and goods is potentially dangerous, since they can be particularly vulnerable to failure.

Because of the high probability of innovation and the tools needed for resilience, an enterprise does not adapt to any detected market transition, but the mental models on how decisions can be taken to promote organizational resilience. In this way, management awareness and behavior connect the behavior of an organization to a evolving world by affecting what is observed, how this data is perceived, and why such decisions are taken (Kaplan 2008). According to this 
perspective, organizational resilience requires two sequential stages, the analysis of the business environment and actual responses (Chattopadhyay, Glick, \& Huber, 2001; White et al., 2003). Precisely, this paper conceives organizational resilience as a two-stage method of using knowledge consisting of the following: logical resilience and instrumental resilience.

Conceptual Resilience: Conceptual resilience applies to the method of obtaining general enlightenment or awareness from business information, and it can be seen as the management beliefs and conceptual models that shape the orientation of managers towards goals, the way they articulate challenges, the variety of strategies they express, and the selection criteria they apply (Moorman 1995). As Cillo et al. (2010) found out, business intelligence is primarily used indirectly during the strategic resilience process to question traditional assumptions and longheld industry representations in order, for example, to analyze the current policy of an organization, to import ideas from other contexts and to envisage alternative consumer approaches. Thus, conceptual resilience relates to the mechanism of information processing in which meaning is provided to information and the mental models of the business environment of decision makers are formed (Menon \& Varadarajan 1992; Moorman 1995).

In both management and marketing literature, this is because managers who operate on a mental model of their environment have been generally accepted (Day \& Nedungadi, 1994; Sinkula, 1994; Thomas et al., 1993). This body of literature shows that the meaning attached to business knowledge evokes corporate behavior (Chattopadhyay et al., 2001). This means a form of sensemaking or categorizing (Thomas et al., 1993) (Dutton \& Jackson 1987; Jackson \& Dutton 1988).

This paper focused on the hazard and opportunity categories as major environmental characteristics, continuing the position of previous research, which are often found to be the two most influential categories in the management decision process (Chattopadhyay et al., 2001). Second, institutional theory indicates that successful organizational behavior also depends on the perception of market knowledge in response to environmental changes, thus a relation between perception and intervention (Thomas et al., 1993). This is because while logical resilience can be defined as the cognitive process offering, the behavioral resilience process is instrumental resilience.

Instrumental resilience: Instrumental resilience applies to the immediate use to satisfy the evolving demands of business awareness (Moorman, 1995). The key subject of the business orientation literature is instrumental resilience, and it includes changes that can vary from smallscale forms such as administrative changes to larger-scale forms such as changes in product / service and policy revision (Jaworski\&Kohli, 1996). Notice that our conceptualization of resilience is compatible with that of Moorman (1995), which demonstrates that resilience is promoted by presenting knowledge about how to make choices. In this article, the emphasis on resilience is different from that of Jaworski and Kohli (1993), which looks at what and how rapidly the organization reacts in the design and execution of marketing campaigns to consumer knowledge. The focus in this paper is more on the adaptability of systems to existing threats and environmental opportunities.

As Dutton \& Jackson (1987) put it, a threat implies a detrimental condition in which loss is inevitable and over which one has very little control (Dutton \& Jackson 1987), and the threat of 
the mark is related to diminished control, possible loss and enhanced anxiety and stress. We argue that the sense of danger may contribute to the rigidity of capital. Second, as pointed out, reduced-control, likely-loss and increased-anxiety and stress are correlated with the principle of danger (Staw et al., 1981). Resilience is pursued by administrators who view risks, reducing the detrimental effect of risks on the enterprise. In the one hand, administrators will concentrate in core business for the intention of growing power, which they will be able to treat for confidence. In the other hand, since the investment risk associated with new domains often amplifies the negative effects, managers are de-motivated to make investments beyond familiar domains. The hazard understanding of the organization then appears to resume market order and retain inertia (Dutton 1993; Hartman and Nelson 1996), contributing to resource rigidity.

\section{Organizational Mindfulness and Resilience}

It is argued that corporate mindfulness leads to the capacity of an organisation to create adaptations until the need is understood. When faced with the need to adapt, communities that can produce different viewpoints, thoughts, expertise, and abilities will have access to a greater arsenal of responses (Ely \& Thomas, 2001; Sutcliffe \&Vogus, 2003). This happens in many forms. Second, because the organisation consists of persons and organizations with a diversity of experience and experiential experiences, it has access to a wider pool of possible reactions to any particular situation (Sutcliffe \&Vogus, 2003). Second, to build completely new responses, those organisations could be best suited.

Analysis shows that communities made up of people of different experience and skills have access to a wider spectrum of cognitive elements that can then be incorporated and recombined into innovative strategies (Amabile, 1983). Finally, by promoting divergent thought during problem solving, organizational mindfulness can promote adaptability (West et al., 2006). It is widely thought that the possible spectrum of innovative ideas is expanded by divergent thought (Nemeth et al., 2001). Therefore, it seems clear that organizational knowledge enhances the capacity to detect and respond to implicit signals that adaptation is necessary. However, without funding for organizing systems and procedures, it is impossible that organisations will be able to produce or rely from them.

Mindful organization is made possible by organizing systems that both establish and rely on mindfulness as a way of preserving adaptability (Weick et al., 1999). In specific, these are mechanisms that help organisations to I identify and use knowledge wisely, (ii) look for new viewpoints and systems and promote them, (c) reflect on the potential for loss, and (iii) learn from errors. Current observational research shows that they are more likely to catch and stop mistakes to the degree that organisations or individuals indulge in mindfulness and conscientious organization (Vogus\& Sutcliffe, 2007). In regards to adaptability, this analysis considers the same set of behaviours.

The organization's leadership plays a vital role in establishing and preserving a framework for mindful organizing, in addition to mindful organizing. They build a framework to translate the advantages of the diversity into organizational performance as leaders search out and use 
diversity in their decision making. In doing so, they also model the practices expected by corporate members to ensure that such diversity continues to find its way into the framework. For instance, when a leader asks for input on a decision or receives support from others, she creates a medium for the data to find its way into the organizational response.

Mindfulness calls for sensitivity to organizational heterogeneity, as this may make some questions of standardization inflexible in multiple local contexts. A mindful organisation, however, has spatial knowledge and is sensitive to its ongoing practices (Weick et al., 1999). This involves developing an impression of the overall condition and organizational state of the organisation, becoming aware of the staff's relationships and dependencies, the organization's function, and the supervision of the work done. The interconnections in the enterprise are seen by individuals who are open to these situational realities and more readily grasp the ambiguity that occurs. Via collaborative narrative building, awareness of current interconnections, diagnosis of shortcomings of expected operations, and mutual mental representations, the resilience is accomplished (Weick et al., 1999; Ciborra et al., 2000; Swanson \&Ramiller 2004). Farb et al. (2007) believe that the organization's mindfulness increases the potential of the organisation for comprehension and empathy. As Goleman et al . 2002) observe that antisocial behaviour arising from the unrestrained and unregulated desire to excel and appear effective more frequently produces an atmosphere of tension, anxiety and work insecurity in which subordinates are continually stressed and overwhelmed with obligations (Hunter \& Chaskalson, 2013), this opinion is also corroborated by Schaufenbuel (2014).

\subsection{Empirical Review}

The connection between organizational mindfulness and responsiveness was explored by Dagogo and Gublin (2020). As a philosophical text, the paper was planned. Therefore, the paper builds on the claims and hypotheses raised by previous studies when it affirms that organizational mindfulness is essential to the growth of intellectual and instrumental sensitivity to sensitive capabilities. In conclusion, it was reported that the collective sense of knowledge and consciousness implemented in the organization's everyday roles and practices go a long way in ensuring that the organization can adapt successfully and meet the environment's shifting and increasing demands. It was consequently proposed that organisations should determine their arrangements and the applicability of their programs and technology in multiple situations on a consistent basis. The applicability of certain attributes influences their efficacy and also affects their resistance.

Okpu and Gbaraka (2019) conducted an analytical investigation into the acceptance and practice of metaphysical components such as management leadership mindfulness and its interaction with social realities, especially as it relates to Nigerian public institutions, such as employee job attitudes in African workplaces. The data for the study was developed as a cross-sectional survey using standardized questionnaires from two agencies based in Port Harcourt. With research finding substantial associations between leader mindfulness and assessments of employee work attitudes, a total of three hypotheses were postulated; Affective engagement, workplace involvement and job satisfaction; suggesting that the implementation and practice of leader 
mindfulness is a prerequisite for successfully managing and managing work-related issues and thus enhancing employee worries In conclusion, the outcomes of this study add credence to its advocacy for the implementation and practice of leadership sensitivity in promoting a more responsive and inclusive work environment and thereby a more desirable representation of employee working attitudes.

\section{METHODOLOGY}

Research Design: This study as a correlational study is designed as a cross sectional surveyand is based on the quantitative methodology. The study descriptively assesses the properties and distribution of the variables, and thereafter inferences are deduced about the relationship between the variables of the study (Sekaran, 2003).

Population: The accessible population for this study comprised of eight (8) hospitality firms. However, our study units include the managerial employees of the firms having that our unit of analysis is at organizational level of the organization. The Department of Human Resources presented us with statistics on operating departments within the organisation. Out of one hundred and sixty-nine (169) jobs, sixty-eight (39) copies were obtained and examined. Owing to their high front-end experiences with the researcher, the chosen companies and respondents were deemed important and representative of the issues the analysis is concerned with (Sarantakos, 2005; Sekaran, 2003).

Instrumentation: During data collection, the standardized questionnaire was introduced. The Ting and Toomey (1999) mindfulness model is focused on observational sources for interpersonal consciousness with measurable effects of mindfulness representing knowledge and partnership skills by questions such as: "my supervisor is a strong listener," "my supervisor often seems involved in my affairs," "my supervisor specifically expresses his desires," and "my supervisor understands www" Three measures, interpersonal adaptability, organizational participation, and customer loyalty are used to assess social realities as articulated by organizational resilience; with metrics for George's adapted measures (2015). Copies of the questionnaire were directly administered to the respective organizations and circulated to participants by the respective administrative officers and clerks of each organization. Each of the variables has 4 elements and is scaled on the 5-point Likert style scale.

Reliability: The reliability of the instrument was ascertained using the reliability coefficient of the test retest. Organizational knowledge (predictor) and organizational stability (criterion variable) were the factors analyzed, which were operationalized using affective participation, organizational commitment and customer loyalty. One month was the time period / interval window allotted between the assessments (Sekaran, 2003). 
Journal DOI: 10.46654/ij.24889849

Table 1: Result for Test Retest Reliability; Source: Research Data, 2020

\begin{tabular}{llll}
\hline Variable & Population_ $\boldsymbol{\mu 1}$ & Population_ $\boldsymbol{\mu 2}$ & Correlation $(\mathbf{R})$ \\
\hline $\begin{array}{l}\text { Organizational } \\
\text { mindfulness }\end{array}$ & 1.9679 & 2.1538 & $0.320(\mathrm{P}<0.005)$ \\
$\begin{array}{l}\text { Affective Commitment } \\
\begin{array}{l}\text { Organizational } \\
\text { involvement }\end{array}\end{array}$ & 1.9359 & 1.9282 & $0.779(\mathrm{P}<0.005)$ \\
Customer Satisfaction & 1.9936 & 1.8808 & $0.346(\mathrm{P}<0.005)$ \\
\end{tabular}

The result for the test retest reveals significant levels of correlation wherein $\mathrm{P}=000<0.05$ in all four instances.

\section{RESULTS AND DISCUSSIONS}

Demographic Analysis: In the analysis, the demographic characteristics studied were focused on the distribution of respondents by gender, age and qualification. The distribution for the demographic data Characteristic of Age, $1=$ less than 25 years; $2=25-35$ years; $3=36-45$ years; and $4=46$ years and above is presented in figure 2 below. The research states that at a percentage frequency of 59 percent, a higher percentage of the participants are male (23), while the female (16) participants account for a percentage of 41 percent. The data also indicates that most of the participants have earned first-degree credentials (59 percent), with the rest also dropping into the 36-45-year-old age group.

Bivariate Analysis: The tests for the hypotheses are undertaken at a 95\% confidence interval(one-tailed).

Table 1: Relationship between organizational mindfulness and organizational adaptability.

$\begin{array}{llll}\text { Model R } & \text { R Square } \quad \text { Adjusted R Square } & \begin{array}{l}\text { Std. Error of the } \\ \text { Estimate }\end{array}\end{array}$

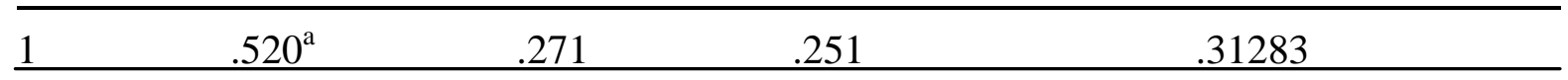

a. Predictors: (Constant), Organizational mindfulness; Source: Research Data, 2020

H1: The practice of mindfulness by the organization will significantly and positively enhance outcomes of organizational adaptability:

As shown in table 1 , the association between organizational mindfulness and organizational adaptability is seen to be important $(\mathrm{R}=.520 ; \mathrm{P}=0.000<0.05)$. The findings also reveal that organizational mindfulness accounts for a 27 percent improvement in organizational adaptability at $\mathrm{R}^{2}=0.27$; so we support the idea that the organization's mindfulness activity can substantially and favorably increase organizational adaptability outcomes. 
Table 2: Relationship between Organizational mindfulness and Organizational involvement.

$\begin{array}{llll}\text { Model R } & \text { R Square } \quad \text { Adjusted R Square } & \begin{array}{l}\text { Std. Error of the } \\ \text { Estimate }\end{array}\end{array}$

\begin{tabular}{lllll}
\hline 1 & $.679^{\mathrm{a}}$ & .461 & .446 & .22797 \\
\hline
\end{tabular}

a. Predictors: (Constant), Organizational mindfulness; Source: Research Data, 2020

H2: The adoption of mindfulness by the organization will significantly and positively enhance outcomes of organizational involvement:

As seen in table 2, the association between organizational mindfulness and organizational engagement is shown to be important $(\mathrm{R}=.697 ; \mathrm{P}=0.000<0.05)$. The findings also indicate that organizational mindfulness is considered responsible for a 46 percent improvement in organizational participation at an $\mathrm{R}^{2}=0.46$; so we support the hypothesis that the organization's acceptance of mindfulness would substantially and positively increase the outcomes of organizational involvement.

Table 3: Relationship between Organizational mindfulness and Customer Satisfaction;

$\begin{array}{llll}\text { Model R } & \text { R Square } \quad \text { Adjusted R Square } & \begin{array}{l}\text { Std. Error of the } \\ \text { Estimate }\end{array}\end{array}$

\begin{tabular}{|c|c|c|c|c|}
\hline 1 & $.728^{\mathrm{a}}$ & .530 & .518 & .18029 \\
\hline
\end{tabular}

a. Predictors: (Constant), Organizational mindfulness; Source: Research Data, 2020

H3: The application of mindfulness by the organization will significantly and positively enhance outcomes of Customer Satisfaction:

As shown in table 3 , the association between organizational mindfulness and consumer satisfaction is seen to be important $(\mathrm{R}=.728 ; \mathrm{P}=0.000<0.05)$. The findings also indicate that corporate understanding can be attributed to a 53 percent improvement in customer satisfaction at an $\mathrm{R}^{2}$ of 0.53 ; hence we support the hypothesis that the organization's implementation of understanding can substantially and favorably increase customer satisfaction outcomes. The findings thus show that all three hypothetical hypotheses (H1, H2, and $\mathrm{H} 3$ ) of positive associations between the variables are acknowledged, based on the results of the study.

Discussion and Implications: This thesis explored the metaphysics of management and social reality in Nigerian companies with an empirical example taken from two hospitality companies in Port Harcourt, Nigeria, exploring organizational knowledge and organizational resilience. In these three examples, a total of three alternative theories on the correlation between organizational knowledge and organizational durability (organizational adaptability, organizational engagement and consumer satisfaction) were evaluated and agreed provided the 
levels of significance observed. As a consequence of the research, this is also discovered that most of the workers within the selected hospitality companies significantly deny that their representatives show concern in the form of recognition and understanding. This low degree of mindfulness found by the chief often correlates to the bad mindset displayed by workers who affirm incidents of alienation, disappointment or loss of interest in the organization's affairs.

The results of these observations are that there is every chance and likelihood that leaders can successfully reach out to workers through increased focus and sound responses to problems concerning them through applying and exercising mindfulness within the workplace. This result is in line with that of Gabriel and George (2015), in which organizational durability is seen to be positively correlated with leader transcendental consciousness and existential thought in terms of engagement, participation and satisfaction; their research corroborates the present in that leadership dimensions that stressed employee respect and gratitude were found to elucidate the present. In addition, the introduction, application and practice of organizational knowledge will also allow the leader's improved capacity to solve challenges and problems, not just from a human-oriented viewpoint, but also from a task-oriented viewpoint, if necessary, provided the non-biased and unsentimental trait of conscientious leadership that bases decisions and behaviors on information as well as real facts.

\section{CONCLUSIONS AND RECOMMENDATIONS}

Conclusion: The results from this report, in conclusion, points to the essential and constructive link between organizational knowledge and organizational resilience. This paper's hypotheses concentrate on the role of organizational knowledge in the resilience of those organizations. The opinions shared herein indicate respect for and an endorsement of the need for corporate understanding of the organization's functionality and procedures as a way to strengthen its intellectual and instrumental resilience. As a result of the reasons raised and the theoretical guidance provided by the organizational awareness imperatives, this paper notes that there is a link between organizational knowledge and resilience and, as such, concludes that the collective sense of understanding and awareness implemented in the organization's everyday functions and practices go a long way to ensure that the organization is resilient and built to survive.

\section{Recommendations}

The following ideas are stated as roles in which mindfulness activities can be strengthened as a way to drive the organization's resilience.

i. Organizations should determine their structures and the applicability of their programs and technology within their different contexts on a regular basis. The applicability of these technologies determines their usefulness and also influences their resistance.

ii. In consideration of its sensitivity and recognition of employee commitment and efforts, and its objectivity in managing conditions and activities within the workplace, the implementation and application of mindfulness by leaders is more likely to promote a more devoted and efficient workforce.

iii. In order to provide the requisite learning assistance, organizational policies should be planned. These policies should also concentrate on finding and resolving the different 
loopholes in the organization's functionality in accordance with strengthening its priorities of efficient resilience to environmental changes.

iv. That the organization's use of mindfulness is more likely to strengthen the interaction between leader and employee due to the responsiveness of leadership to employee involvement, which will further promote employee organizational participation and engagement.

v. Stability and adaptability can also be underlined by corporate processes and mission arrangements. In conscientious organization and preparation, these are critical and reflect a readiness for transition or a more efficient stance towards increasingly competitive and uncertain market environments.

vi. The organization's implementation and incorporation of mindfulness is more likely to match leadership with workforce problems, obstacles and working environments that can increase employee customer loyalty and identification of their positions when successfully handled. 


\section{REFERENCES}

Amabile, T. M. (1983). The social psychology of creativity - a componential conceptualization. Journal of Personality and Social Psychology, 45(2), 357-376.

Chattopadhyay, P, Glick, W.H \&. Huber G.P (2001). Organizational actions in response to threats and opportunities, The Academy of Management Journal, 44(5), 937-55.

Dagogo, T. M., \&Gublin, S. D. (2020). Organizational mindfulness and responsiveness: a conceptual review. European Journal of Business and Innovation Research. 8(2), 20 -29.

Day, GS., \&Nedungadi P (1994). Managerial representations of competitive advantage, Journal of Marketing, 58(2), 31-44.

Dimov, D. P., Shepherd, D. A., \& Sutcliffe, K. M. (2007). Requisite expertise, firm reputation and status in venture capital investment allocation decisions. Journal of Business Venturing, 22, 481-502.

Dreyer, B., \& Grønhaug, K. (2004). Uncertainty, flexibility, and sustained competitive advantage. Journal of business research 57(5), 484-494.

Dutton, JE. \& Jackson SE (1987). Categorizing strategic issues: Links to organizational action, Academy of Management Review, 12(1), 76-90.

Ely, R. J., \& Thomas, D. A. (2001). Cultural diversity at work: The effects of diversity perspectives on work group processes and outcomes. Administrative Science Quarterly,46(2), 229-273.

Graetz, F., \& Smith, A. C. (2009). Duality theory and organizing forms in change management. Journal of Change Management 9(1), 9-25.

Grewal, R., R. \& Dharwadkar. (2002). The role of institutional environment in marketing channels. Journal of Marketing 66(3) 82-97.

Hartman, Sandra J., \& Beverly H. Nelson (1996). Group decision making in the negative domain, Group \& Organization Management, 21(2), 146-62.

Hatum, A., \& Pettigrew, A. M. (2006). Determinants of organizational flexibility: a study in an emerging economy. British journal of management 17(2), 115-137.

Huber GP. (2004). The necessary nature of future firms. Sage Publishers, Thousand Oaks, CA Hult, G. T M., David J. K, \& Stanley F. S (2005). Market orientation and performance: an integration of disparate approaches, Strategic Management Journal, 26(12), 1173-81.

Jackson, SE.,\& Dutton JE (1988). Discerning threats and opportunities, Administrative Science Quarterly, 33(3), 370-87.

Kaplan, Sarah (2008). Cognition, capabilities, and incentives: Assessing firm response to the fiber-optic revolution and hypotheses, Academy of Management Journal, 51(4), 672- 95. 
Kohli, Ajay K., \& JaworskiB.J (1990). Market orientation: The construct, research propositions and managerial implications, Journal of Marketing, 54, 1-18.

Kraatz, M.S. \& Zajac, E.J. (2001). How organizational resources affect strategic change and performance in turbulent environments: Theory and evidence. Organization Science12(5): 632

March, JG, \& ShapiraZ (1987). Managerial perspectives on risk and risk taking, Management Science, 33(11), 1404-18

Martínez-Sánchez, A., Vela-Jiménez, M. J., Pérez-Pérez, M., \& De-Luis-Carnicer, P. (2009). Inter- organizational Cooperation and Environmental Change: Moderating Effects between Flexibility and Innovation Performance. British Journal of Management 20(4), 537-561

Menon, A, \&Varadarajan PR (1992a). A model of marketing knowledge use within firms, Journal of Marketing, 56(4), 53-71.

Meyer, J. W., Rowan, B. (1977) Institutionalized organizations: formal structure as myth and ceremony. The American Journal of Sociology. 83(2):340-363.

Moorman, C (1995). Organizational market information processes: Cultural antecedents and new product outcomes, Journal of Marketing Research, 32(3), 318.

Nemeth, C. J., Connell, J. B., Rogers, J. D., \& Brown, K. S. (2001). Improving decision making by means of dissent. Journal of Applied Social Psychology, 31(1), 48-58

Okpu, T., \&Gbaraka, K. A. (2018). Leader mindfulness and employee work attitudes in public agencies in Port Harcourt. The Academy of Management Journal, 44(5), 937-55.

Sanchez R. (2003). Commentary. In R. Garud, A. Kumaraswamy, and R. N. Langlois (Eds.), Managing in the modular age. Blackwell Publishers, Malden, MA

Schilling MA. (2000). Toward a general modular systems theory and its application to interfirm product modularity. Academy of Management Review 25(2): 312-334.

Sinkula, James M. (1994), -Market Information Processing and Organizational Learning,Journal of Marketing, 58(1), 35-45.

Staw, Barry M, Lance E Sandelands, \& Jane E Dutton (1981). Threat-rigidity effects in organizational behavior: A multilevel analysis, Administrative Science Quarterly Science, 26(4), 501-24.

Suarez, F.F., Cusumano, M.A., \& Fine, C.H. (2003). Flexibility and performance: a literature critique and strategic framework. Massachusetts Institute of Technology: Cambridge, MA

Sutcliffe, K. M. (2000). Organizational environments and organizational information processing. In F. Jablin \& L. Putnam (Eds.), Handbook of organizationalcommunication: Advances in theory, research and methods, 197-230. Beverly Hills: Sage

Sutcliffe, K. M., \&Vogus, T. (2003). Organizing for resilience. In K. Cameron, J. E. Dutton \& R. E. Quinn (Eds.), Positive organizational scholarship. San Francisco: Berrett-Koehler 
Thomas, JB, Shawn MC, \& Dennis A.G (1993). Strategic sense making and organizational performance: linkages among scanning, interpretation, action, and outcomes. Academy of Management journal, 36(2), 239-70.

Verdú-Jover, A. J., Lloréns-Montes, F. J., \& García-Morales, V. J. (2006). Environmentflexibility coalignment and performance: an analysis in large versus small firms. Journal of Small Business Management 44(3), 334-349.

Vogus, T., \& Sutcliffe, K. M. (2007). The impact of safety organizing, trusted leadership, and care pathways on reported medication errors in hospital nursing units. Medical Care, 45(10), 997-1002

Volberda, H. (1998). Building the flexible firm: How to remain competitive. Oxford, UK: Oxford University Press.

Volberda, H.W., Ende, J.C.M., Van den, Ark, H.H., Rotmans, J., Soete, L.L.G. \& De Vries, N.K. (2007). What matters most for innovation? Multi-level complementarities between knowledge creation, transfer and utilization, Proposal for NWO-MaGW strategic theme 2007-2010, 32.

Weick, K.E. (1998). Introductory essay. Improvisation as a mindset for organizational analysis. Organization Science, 9(5), 543-555

Weick, K.E., and Sutcliffe, K.M. (2006). Mindfulness and the quality of organizational attention. Organization Science, 17(4), 514-524.

West, M. A., Sacramento, C. A., \& Fay, D. (2006). Creativity and innovation implementation in work groups: The paradoxical role of demands. In L. Thompson \& H.-S. Choi (Eds.), Creativity and innovation in organizational teams. London: Lawrence Erlbaum Associates.

White, J.C, P. Rajan Varadarajan, \& Peter A. Dacin (2003). Market situation interpretation and response: The role of cognitive style, Organizational culture, and information Use, Journal of Marketing, 67(3), 63-79.

Winter SG. (2003). Understanding dynamic capabilities. Strategic Management Journal 24, 991 995.

Worren N, Moore K, Cardona P. (2002). Modularity, strategic flexibility, and firm performance: A study of the home appliance industry. Strategic Management Journal23: 1123-1140

Zucker, L. G. (1987). Institutional theories of organization. American Review of Sociology13(1): 443-464. 